AsCLEPIO. Revista de Historia de la Medicina y de la Ciencia

66 (2), julio-diciembre 2014, p055

ISSN-L:0210-4466

http://dx.doi.org/10.3989/asclepio.2014.19

DOSSIER: BIOPODER Y DETERMINISMOS EN SUDAMÉRICA DURANTE EL SIGLO XX / DOSSIER: BIOPOWER AND DETERMINISM IN SOUTH AMERICA DURING THE TWENTIETH CENTURY

\title{
IGLESIA CATÓLICA Y EUGENESIA LATINA: UN CONSTRUCTO TEÓRICO PARA EL CONTROL SOCIAL (ARGENTINA, 1924-1958)
}

\author{
Gustavo Vallejo y Marisa Miranda \\ Conicet, Argentina \\ vallejomiranda@yahoo.com.ar
}

Recibido: 3 diciembre 2013; Aceptado: 14 abril 2014.

Cómo citar este artículo/Citation: Vallejo, Gustavo y Marisa Miranda (2014), “Iglesia católica y eugenesia latina: un constructo teórico para el control social (Argentina, 1924-1958)", Asclepio, 66 (2): p055. doi: http://dx.doi.org/10.3989/asclepio.2014.19

\begin{abstract}
RESUMEN: Se abordan aquí interacciones entabladas entre ciencia y religión a través de la formulación de un saber particularmente influyente en el campo del poder, como fue el conformado en torno a una corriente de pensamiento eugénico. Nos referimos a la variante gestada desde la biotipología italiana para atender al control social impulsado por el fascismo y también por países como la Argentina donde llegó a sobrevivir en el tiempo más allá de la segunda posguerra. Esa versión eugénica, caracterizada por un encendido rechazo a cualquier acción pública o privada orientada a la esterilización humana -atento al mandato católico de no intervención sobre los cuerpos, gestión privativa de Dios- propició medidas también tendentes a acelerar una selección artificial vulnerando todo principio de igualdad humana. Tomando la postura oficial de la Iglesia católica ante la eugenesia, entre 1924 y 1958, su relación con la biotipología y la difusión en Argentina de la llamada eugenesia latina, en tanto expresión resultante de esa articulación entre ciencia y religión, se busca dar cuenta de la coexistencia en ese constructo de la identificación, clasificación, jerarquización y exclusión de individuos que caracteriza a todo planteo eugenésico, instrumentados merced a dispositivos coercitivos de índole ambiental.
\end{abstract}

PALABRAS CLAVE: Eugenesia Latina; Iglesia Católica;Biotipología; Control Social; Argentina.

\section{CATHOLIC CHURCH AND LATIN EUGENICS: A THEORETICAL CONSTRUCT FOR THE SOCIAL CONTROL (ARGENTINA, 1924-1958)}

ABSTRACT: This paper discusses interactions between science and religion thorough the formulation of the Italian Biotipology, as knowledge very influential in the field of power. That ideology was created around a variant of the eugenic thinking for to give answers to the social control promoted by the fascism; and it was well accepted in different countries, as Argentina, for example. Here, it survived over several years beyond the World War II. The Biotipology was characterized by a strong repulse to any public or private action oriented to human sterilization. Indeed, we must remember that Catholic rules imposed the "no-intervention on the bodies", belonging only to God. On these corpus of ideas, the new Italian science prompted arrangements that attempt to accelerate the artificial selection breaking the human equality principle. Between 1924 and 1958, the Biotipology was the official Catholic doctrine about Eugenics and it was widespread in Argentina from the called Latin Eugenics. In this manner, the identification, classification, hierarchical structure and exclusion of some humans, were instrumented in this country by means of coercive and environmental devices.

KEY WORDS: Latin Eugenics; Catholic Church; Biotipology;Social Control; Argentina.

Copyright: (c) 2014 CSIC. Este es un artículo de acceso abierto distribuido bajo los términos de la licencia Creative Commons Attribution-Non Commercial (by-nc) Spain 3.0. 
INTRODUCCIÓN: ¿CONTRA EL DETERMINISMO BIOLÓGICO, UN FATALISMO AMBIENTAL «POSITIVO»?

Sabido es que después del Holocausto el concepto de eugenesia pasó a integrar una axiología que impidió mantenerse indiferente o distante ante sus connotaciones. Subyacía una carga semántica que pareció totalizar la idea del mal absoluto y, ante ella, una reacción cultural apuntó a mantener el compromiso ético de su condena, mientras, casi tranquilizadoramente, tendía a confinarlo a un tiempo y lugar, concretos, pero distantes. Vale decir, existió una época y un régimen político para hacer prosperar la eugenesia que la confinaron a una aparente historia superada e irrepetible, al menos desde la Declaración Universal de Derechos Humanos de 1948. Esta certeza se asentó, además, sobre otras que confluyeron en patrones organizados en torno a una lógica binaria presente, también, en visiones historiográficas que abordaron el problema. En este sentido, un lugar común ha sido asociar el concepto de eugenesia a la esterilización compulsiva aplicada por el nazismo y, aunque menos tratado, por diversas jurisdicciones de los Estados Unidos (Stern, 2005, Stern, 2010); restando trascendencia a aquello que no se expresara a través de una violencia física manifiesta. Esa medida forzada marcaría los límites del concepto mismo de eugenesia, y el interés por su abordaje, que en el caso latinoamericano inicialmente se desplazó hacia una exaltación de las interferencias al desarrollo de esa "eugenesia dura». De ese modo se alimentaron estereotipos que contribuyeron a afianzar la imagen de la Iglesia católica como una expresión anti-eugenista que habría resultado clave para hacer prosperar «progresistas» perspectivas neolamarckianas, favorecedoras de una mejora colectiva, transmisible hereditariamente merced a la incidencia del ambiente ${ }^{1}$. Al insistir en remarcar la directa vinculación entre eugenesia y determinismo biológico, esa perspectiva dejó en pie la posibilidad de romper el fatalismo de la "eugenesia dura» desde el libre albedrío y las posturas ambientales que, en este juego de contrastes, correspondían a las características de una religión y su preeminencia en sociedades de ascendencia latina. Asimismo, el liberalismo, a través de la defensa de los derechos civiles inmanentes a su corpus teórico, también fue visto como otro factor condicionante del avance de toda forma de determinismo. De esta manera, en América Latina en general $y$, en la Argentina, en particular, se afirmó una mirada historiográfica según la cual sólo pudo prosperar una eugenesia valorada como "positiva» por efecto de la moderación del liberalismo y la influencia de la Iglesia católica que hicieron que ella fuera «menos eugénica» y más cercana al higienismo. En consecuencia, el ambientalismo cultivado habría incidido en el carácter "encomiable» que tuvieron experiencias entendidas como expresión antitética del determinismo, siempre asociado a un plano biológico².
Sin embargo, una lectura más atenta de las circunstancias que rodearon el nacimiento de una forma de eugenesia propagada en países de ascendencia latina durante el siglo XX, nos permite ver esa variante como una expresión de otro tipo de coerción. En este caso se trató del control social impulsado por el fascismo italiano, en directa relación con anhelos emanados de normativas eclesiásticas y trasladados a países como la Argentina por voluntad de elites dirigentes enroladas en un liberalismo que, redefiniendo en la praxis sus principios básicos, se manifestó deseoso de poner orden en la sociedad aun a expensas de condicionar libertades individuales.

Buscaremos aquí trascender los mencionados estereotipos para poder abordar con mayor libertad conceptos capaces de explicar el desarrollo de una eugenesia que, si bien se mantuvo claramente diferenciada de la anglosajona, también estaría signada por un alto grado de coerción y de violencia simbólica. Nos interesa ver cómo Iglesia católica y eugenesia coincidieron en una articulación entre saberes científicos y dogmáticos que produjo un constructo signado por un fatalismo, en este caso de tipo ambiental.

Al indagar algunos de los aspectos que permiten extender el concepto de eugenesia más allá de su directa asimilación a las esterilizaciones, buscamos echar luz sobre los principios que encierra la noción de eugenesia latina en tanto expresión irradiada en diversos países a partir de una formulación nacida en la Italia del Duce e imbricada de manera indisociable con el mandato confesional. En ella coexistieron la identificación, clasificación, jerarquización y exclusión de individuos como estrategias características de todo planteo eugenésico, instrumentados merced a diversos dispositivos de control social que, en este caso, se desplazaron del determinismo biológico a un fatalismo ambiental "positivo».

Fue durante la década de 1920 cuando se perfilaron los rasgos que distinguirían a la eugenesia latina dentro del marco de difusión de la ciencia de Galton a nivel internacional. Acontecimientos como los distintos congresos que sucedieron al organizado en 1912 por Leonard Darwin en Londres, el desarrollo de la Gran Guerra y la irrupción del fascismo en Italia, signaron la consolidación de un constructo bien delimitado. Sobre el mismo, la Iglesia católica desplegó un destacado rol que cabe analizar desde dos perspectivas: la que hace a la incidencia del dogma religioso en las características ontológicas de esa eugenesia, por una parte, y la que remite a una instrumentación a través de su inserción en la praxis evangelizadora, por otra. Si bien es cierto que Francis Galton pensó su disciplina como una religión del futuro y muchos de sus 
seguidores creyeron en la potencia unificadora de un saber que podía trascender la esfera de lo científico, la posición vaticana introdujo una clara cisura dentro de la eugenesia en el plano internacional. Ello nos permite identificar entre catolicismo y eugenesia una problemática centrada en la influencia directa del primero en los medios y fines definidos por la segunda, y, a la vez, indagar los mecanismos de apropiación y difusión del discurso eugénico a través del accionar de ámbitos católicos.

\section{EL DOGMA RELIGIOSO EN LA ONTOLOGÍA DE LA EUGENESIA LATINA}

Una figura central en el entramado tejido entre ciencia y religión que confluiría en la eugenesia latina, fue en Italia Agostino Gemelli, médico socialista que tras renunciar a esa filiación se convirtió al catolicismo y en 1921 fundó la Universidad Católica del Sacro Cuore. Gemelli rápidamente accedió a las más altas esferas del Vaticano y desde allí impulsó la relación entre el movimiento eugénico internacional y la Iglesia católica, teniendo participación central en el diseño de las políticas demográficas implementadas por el fascismo italiano ${ }^{3}$.

Su intervención en el 1ㅇ Congreso Italiano di Eugenetica Sociale, celebrado en 1924 en Milán, planteó tempranamente una problemática sobre la que se terminaría conformando el núcleo constitutivo de una vasta corriente de pensamiento. Allí disertó sobre "Eugenetica e religione», sosteniendo que «el catolicismo es, en efecto, también una doctrina eugénica ${ }^{4}$, para reclamar que un país católico como Italia tuviera la colaboración de los eugenistas médicos con la Iglesia, atentos a la norma moral con que se rige la humanidad así como por la naturaleza intrínseca de su doctrina. Desde esta perspectiva, la cooperación entre religión y eugenesia revelaba la armonía fundamental que debía existir entre la fe y la ciencia (Gemelli, 1924: pp. 732-733), para que en lugar de la «incultura» de los que proponían la esterilización obligatoria de los criminales, prosperara la «eugenética social» católica (Gemelli, 1924, p. 735). En su misión de realizar la "más racional de las acciones eugénicas», la Iglesia impulsaba la castidad de «quienes traerían al mundo seres fatalmente afectados de una enfermedad hereditaria» (Gemelli, 1924, pp. 747-748) concluyendo que la Iglesia, lejos de ser enemiga de la eugenesia, operaba como su complemento imprescindible, ya que "la norma eugénica tendrá una aplicación más eficaz en su integración con la moral católica» (Gemelli, 1924, p.750).

El Vaticano, a través de voces autorizadas como la de Gemelli, exhibía así su voluntad de complementar desde la religión los avances que realizaba Nicola
Pende a través de la biotipología ${ }^{5}$. En efecto, Pende en 1922 había lanzado una disciplina científica encargada de ahondar en lo profundo del ser a través de un desplazamiento de la antropología física a la antropología endócrina, que era inclusivo a su vez de los aportes que le proveía la unidad sustancial entre cuerpo y alma sostenida por el pensamiento aristotélico-tomista. Se trataba de la biotipología, nacida para detectar alteraciones individuales de tipo hormonal y moral capaces de transmitirse a la esfera social. Con ese fin llevó la preocupación de Lombroso por estudiar las disgenesias de quienes poseían un visible apartamiento de la normalidad hasta límites insospechados. Para llegar a la verdad que podían ocultar las apariencias, hacía falta analizar particularizadamente a cada uno de los integrantes de toda la población, desenmarañando los infinitos obstáculos que interferían ese propósito cuando un cuerpo sano escondía un alma criminal ${ }^{6}$. Este objetivo buscó ser alcanzado a través del fichaje biotipológico en el que se cruzaba información sanitaria y confesional, donde el médico y el religioso confluían en el examen particularizado y totalizante de la población. Su completa articulación se terminó de plasmar con Pende y Gemelli asumiendo el rol de principales organizadores de una variante eugénica que concitó, desde un principio, el explícito aval del Duce y del Vaticano. De hecho, una rama central de la biotipología italiana sería la psicotecnia que quedó a cargo del propio Gemelli quien, desde allí, buscó potenciar en el hombre sus funciones de servir mejor «a los eternos ideales de la sociedad humana: Familia, Patria y Religión» (Vallejo, 2008, p. 32).

Paralelamente, promediando la década de 1920 ya tenían trascendencia internacional las esterilizaciones de grupos «peligrosos» que, amparados legalmente en nombre de la eugenesia, se llevaban a cabo en el sur de los Estados Unidos (Stern, 2005). El tema, que daría una amplia popularidad a figuras como Harry Laughlin y Paul Popenoe, motivaría en la jerarquía vaticana una respuesta contundente. Así, en diciembre 1930, Pío XI dictó la Encíclica Casti Connubii con la intención de sentar una postura respecto a la cuestión. Sin embargo, su lenguaje alambicado suscitó interpretaciones encontradas y la necesidad de generar posteriores aclaraciones.

Una lectura superficial del documento contribuyó a afirmar la certeza de su oposición de plano a la política eugénica, siendo, en verdad, una declaración eminentemente contraria a las esterilizaciones, más no a la selección de futuros cónyuges a través de consejos prematrimoniales para garantizar una prole "sana», física y moralmente. Allí se destacaba la conveniencia de desalentar, por vía de consejo sacerdotal, las uniones matrimoniales de aquellos que no harían más que «engendrar hijos defectuosos» (Pío XI, 1930, punto 24). 
Pero lo sinuoso de un texto que se prestaba a la recepción ambigua de sus mandatos, llevó a que poco después el Vaticano dictara el Decreto del Santo Oficio fechado el 21 de marzo de 1931. La nueva norma buscó precisar los criterios enunciados en la Casti Connubii, dejando en claro una condena a la eugenesia, que, en verdad, lo era al neomaltusianismo, al que se lo asociaba a la educación sexual y a los métodos de control de la natalidad, ya sea éste voluntario o compulsivo (Osés, 1931-a, p. 7).

Asimismo, una nueva aclaración provino del Cardenal Gomá7 al publicar su Explicación dialogada de la Casti Connubii, también en 1931, para destacar la «finalidad eugénica» del matrimonio, sosteniendo que

todo cuanto sea mejorar la naturaleza del hombre, tanto en su aspecto físico o corporal como en su parte espiritual o moral, no puede menos que merecer la aprobación de la santa Iglesia...... Ni puede la Iglesia desentenderse de una legítima preocupación por la procreación de hijos sanos, física y moralmente, y por la transmisión de la vida en las mejores condiciones posibles. Lo que ella reprueba, dice un médico famoso, no es un eugenismo normal y legítimo, sino este otro que ha pactado con el neomaltusianismo una alianza desdichada, y que emplea medios contrarios al verdadero fin del matrimonio, tal como lo define la moral católica (Gomá, 1943, p. 153).

Esta lectura autorizada de la Casti Connubii que confirmaba el criterio seguido por el Vaticano al vincularse simbióticamente con la eugenesia latina, sería complementada por nuevas precisiones que Gomá haría públicas en su visita a la Argentina en 1934. En el Día de la Raza dictó la conferencia «Apología de la Hispanidad» en el Teatro Colón de Buenos Aires (Gomá, 1934), dentro de las actividades comprendidas en el multitudinario Congreso Eucarístico Internacional que se celebró entre el 10 y el 15 de octubre de ese año y que tuvo como protagonistas a Gemelli y al Cardenal Eugenio Pacelli -posteriormente Papa Pío XII-. El evento precedió a la Segunda Conferencia Panamericana de Eugenesia y Homicultura ${ }^{8}$, que se desarrollaría también en Buenos Aires, poniéndose aquí de manifiesto estrategias geopolíticas internacionales desplegadas a través de distintas redes eugénicas que tenían a la Argentina como un claro punto de tensión. Mientras Estados Unidos trataba de instrumentar mecanismos de control de la inmigración a través de datos genéticos y somáticos recabados para centralizar la información racial de las poblaciones del continente mediante la homicultura (Álvarez Peláez y García González, 1999), el Vaticano e Italia tendían a contrarrestar aquella influencia por medio de una precisa política cultural para que, a través del impulso de las máximas autoridades eclesiásticas y Nicola Pende, respectivamente, afirmaran una eugenesia latina capaz de canalizar eficazmente los anhelos de naciones católicas americanas y europeas (Vallejo, 2007, p. 216).

\section{LA EUGENESIA LATINA EN LA PRAXIS EVANGELIZADORA}

En Argentina la eugenesia autorizada por el Vaticano originó intensas reflexiones dirigidas a darle una precisa instrumentación, como la perseguida desde la revista católica Criterio $^{9}$. En el interregno de algo más de dos meses durante el cual la Casti Connubii marchó sola, es decir, sin las aclaraciones antes mencionadas, un texto especialmente escrito desde Roma enfatizó la oposición a las esterilizaciones y, en general, al control de la natalidad sustentado por la «propaganda de la eugenética, engañosamente conceptuada» (Sanvisenti, 1931, p. 283).

Luego, y reforzando esa línea argumental, volvió sobre el rechazo al neomaltusianismo, considerado un «ataque contra la familia» (Osés, 1931-b, p. 41) inmerso en la prohibición emanada del Sumo Pontífice de los «procedimientos contrarios a la naturaleza y a la libertad y santidad del matrimonio con el pretexto de mejorar la raza humana y de disminuir la natalidad, sobre todo en los matrimonios pobres» (Franceschi, 1932, p. 130). Asentados en «el egoísmo humano y la soberbia seudocientífica», causaban más crímenes que «que la Gran Guerra europea o la mayor de las pestes que han afligido a la humanidad» (Franceschi, 1932, p. 130).

Paralelamente a estas advertencias, eran atendidos aspectos vinculados a las uniones deseables, aquellas que contenían la obligación moral que debía asumir todo padre "prudente y razonable» de averiguar los «antecedentes familiares, en lo tocante a la salud de su futuro yerno o de la novia de su hijo», porque con ello, en verdad, se estaba haciendo una obra de «eugenesia legítima» (Ochoa, 1931- a, p. 147). En efecto, desde allí se consideraba que no había nada de «irrazonable ni de ilegal» (Ochoa, 1931-a, p. 147) en la eugenesia, ya que el amor, en sí mismo, era visto como un proceso de selección:

nadie se enamora normalmente de un cretino, de un loco, de un fenómeno, si no, por el contrario, de quien, a sus ojos, es bien parecido y adornado de bellas cualidades. Lástima que esta imperfecta e instintiva selección del amor sea neutralizada en inmensidad de casos por el interés o por las conveniencias sociales: la selección natural, queda vencida en medios sociales secos y estériles afectivamente (Ochoa, 1931-b, p. 309).

El «desorden moral de los pueblos» había generado el «envenenamiento de la raza, su decaimiento, su degeneración», así como el "extraordinario número de tarados de que se quejan los países más adelantados del mundo» (Ochoa, 1931-b, p. 309).

En Criterio también se criticó a El matrimonio perfecto $^{10}$, al que burlonamente se lo llamó «el matrimonio depravado», para celebrar luego la «justa» decisión de la Congregación del Santo Oficio de haber incluido ese libro en su Índice (Ochoa, 1931-c, p. 475). 
En buena medida, estas ideas pueden ser integradas a la eugamia, una disciplina gestada en España por Antonio Vallejo Nágera ${ }^{11}$, figura de referencia para Criterio y distintos eugenistas argentinos. Durante los primeros años del franquismo, la eugamia fue entendida como el medio que permitiría «casar selectos para parir selectos» (Vallejo Nágera, 1938). El programa incluía la propuesta de instaurar un certificado médico estatal para impedir el apareamiento de enfermos y tarados (Vallejo Nágera, 1943, p. VII), el cual debía necesariamente ser complementado por la intervención del "médico de las almas», el confesor o un "sacerdote prudente», para que -en el supuesto de haberse encontrado obstáculos en la salud de los contrayentes- evaluara la conveniencia o necesidad del matrimonio, puesto que todo lo temporal debía quedar subordinado a las obligaciones morales y a la propia salvación (De Sobradillo, 1943, p. 159).

Desde Criterio se siguió la intervención de Vallejo Nágera en el Segundo Congreso Internacional de Médicos Católicos, celebrado en Viena entre el 28 de mayo y el 3 de junio de 1936. En esa ocasión, el español coincidió con Gemelli quien era por entonces rector de la Universidad de Milán y concurrió al Congreso en representación del Papa Pío XI. Las posturas que Vallejo Nágera y Gemelli defendían confluyeron en un programa común que implicaba el ataque a la esterilización, entendiendo que se apartaba de la verdadera eugenesia, pues consideraban que bastaba la Encíclica Casti Connubii para que "la medicina y en especial la eugenesia moderna vieran al gran Pío XI como su gran bienhechor» ya que la ciencia confirmaba como postulado biológico lo que él, con una «ciencia mucho más alta» había aconsejado y ordenado antes (Petrus Canisius, 1936). Con el papel preponderante que tuvieron allí Vallejo Nágera y Gemelli, el encuentro de Viena concluyó en que la eugenesia verdadera está de completo acuerdo con la doctrina católica, merece el apoyo de todas las hermandades médicas e invita a promoverla en todos los países (O'Lery, 2008, p. 370).

Paralelamente, iban identificándose en el neomalthusianismo extendidas ramificaciones que debían ser atacadas. Una de ellas fue la que llevó en Argentina, al militante católico Manuel Blanco a focalizar su interés eugénico en combatir el onanismo. Una vez llevada a cabo la selección eugámica, quienes eran considerados aptos para procrear debían hacerlo ilimitadamente. Por esta razón, consideraba onanista a «todo procedimiento que tiene por objeto evitar la concepción», tanto el «autoerotismo» como el birth control (Blanco, 1946, p. 38). Un acto onánico era aquel en el que

no se elimina a un ser solamente, sino a todos los que en el futuro proviniesen de él, es decir, se corta la vida a una generación futura y a tantas ramificaciones que de él descendieran; por lo cual en este caso el pecado es múltiple y colectivo (Blanco, 1946, p. 26).
Bajo esta perspectiva se sostenía un pronatalismo fundado en un control paroxístico de la reproducción selectiva. De ahí que considerara "escandaloso» a un matrimonio joven que, tras pasar por la instancia de aprobación de la Iglesia, acudiera tan sólo «cada cuatro o cinco años» a llevar «un hijo a bautizar» (Blanco, 1946, p. 61).

Para el pensamiento católico el matrimonio prolífico, una vez superada la instancia aprobatoria de los consejos prematrimoniales, y la castidad y continencia para quienes se hallaban en una etapa previa o habían sido expresamente rechazados por dichos consejos, conformó un extendido programa de promoción de la eugenesia.

Podría inferirse que la postura católica dirigida a controlar la reproducción a través de los consejos prematrimoniales y la continencia, constituía una utopía tan irrealizable como la que llevó a Pende a buscar clasificar a toda la población para detectar el «justo lugar» que debía ocupar cada individuo dentro de la sociedad, valiéndose para ello de fichajes biotipológicos de toda la población, emprendimiento que, a todas luces, resultaría impracticable (Ferla, 2009). Sin embargo, tanto en un caso como en el otro, la difusión de un "modelo ejemplar» a ser seguido, permitía definir un particular patrón de normalidad y, por ende, de anormalidad respecto a todo lo que se apartaba de él. La detección y apartamiento de esa entidad "anormal», podía ser objeto de estrategias como las impulsadas desde el campo jurídico, que contaba en Argentina con los recursos teóricos de un liberalismo travestido por una praxis poco consecuente con la defensa de las libertades civiles y que detentaba un significativo capital simbólico. Dentro de este marco, del muy influyente jurista argentino Enrique Díaz de Guijarro ${ }^{12}$, podían surgir propuestas como el impulso al self control de la sexualidad, por entenderse que la sexualidad sólo sería «aceptable cuando estuviera moralmente controlada», al considerar desde el plano jurídico a "la religión el mejor sistema de moral que existe» (Díaz de Guijarro, 1948, p. 26).

Sexo, procreación y moralidad eran considerados como un todo integrado, formando parte de un sistema que, desde una mirada católica asociada a una doctrina jurídica liberal, interpretaba la ley natural a partir del imperativo moral que debía orientar a los esposos en el riguroso deber de asegurar a su descendencia toda la pureza y la salud requerida. En efecto, para lograr el control de la calidad era necesario cultivar en distintas etapas de la vida, "la continencia, la castidad, la moralización de las almas», que en su conjunto conformaban «la eugenesia más eficaz, el cumplimiento intransigente de la moral católica» (Díaz de Guijarro, 1948, p. 28). 
Otro jurista liberal, en este caso Carlos Bernaldo de Quirós, padre del Derecho Eugénico Argentino ${ }^{13}$, proseguiría en la misma línea que Díaz de Guijarro, promoviendo una educación de la continencia, que además de garantía de moralidad tenía importantes efectos saludables revelados en el "valor útil del semen retenido en las vesículas» (Bernaldo de Quirós, 1960, p. 97). En este contexto, Bernaldo de Quirós sostenía que la educación sexual debía situarse en un plano trascendente a la conducta individual para imbricarse con un destino colectivo: "el porvenir de nuestra raza depende de la educación sexual», el cual debía forjarse desde la raíz de los problemas, es decir, desde la "preservación de la herencia» y el «saneamiento moral, ambiental». Las enseñanzas de la Iglesia sostenían ejemplarmente "su doctrina y práctica contra el llamado instinto sexual», de donde deducía que "el alma casta es el máximo valor» y "practicar la castidad es recibir 'innumerables bendiciones de Dios» (Bernaldo de Quirós, 1960, pp. 105-106).

Díaz de Guijarro y Bernaldo de Quirós prolongaban en el derecho, inquietudes que desde los años'30 venían siendo tematizadas por intelectuales católicos. El problema de la continencia y la castidad como parte de una educación sexual acompañada de acciones recomendadas por sus beneficios en el orden psíquico y fisiológico, ya había sido planteado en el Congreso de la Nación por el diputado católico Juan Cafferata, en ocasión de debatirse el proyecto de profilaxis de las enfermedades venéreas presentado en 1935 y simultáneamente reflejado en las páginas de Criterio (Cafferata, 1935).

El Derecho Eugénico de Bernaldo de Quirós también abrevó en las recomendaciones que el húngaro Tihamer Toth volcó a Eugenesia y Catolicismo, obra de la que circularon varias ediciones en español desde la primera aparecida en 1940. Tras preguntarse por las enseñanzas del catolicismo sobre la eugenesia, condenaba «la eugenesia meramente materialista» por pretender "aplicar a los valores de la vida humana la medida con que se mide la cría de animales» y pregonar "el colectivismo» y «la esterilización de hombres inocentes». En cambio había otra eugenesia que para regocijo del Vaticano se basaba en «el gran esfuerzo que intenta asegurar una generación humana más valiosa, más sana, más fuerte, más resistente en el trabajo» (Bernaldo de Quirós, 1966, p. 209).

En definitiva, y siguiendo las recomendaciones de Toth, la verdadera eugenesia que debía ser impulsada desde el derecho era aquella "más valiosa que cualquiera otra» la del "pregonar la vida completamente pura hasta el matrimonio y exigir a los cónyuges una vida moral» (Bernaldo de Quirós, 1966, p. 209).

\section{LA IGLESIA CATÓLICA ANTE LA EUGENESIA DE LOS NACIONALISMOS}

La precisa delimitación del tipo de eugenesia promovida frente a aquella que era rechazada implicó también asumir una posición ante la emergencia de distintos nacionalismos europeos en el período de entreguerras. Las disidencias mayores, claro está, residían ante el nazismo debido fundamentalmente a dos cuestiones que el Padre Julio Menvielle ${ }^{14}$ sintetizaba en la pretensión de Hitler de crear una nueva Iglesia estrictamente alemana, y en la «ley anticristiana que imponía la esterilización forzada de toda persona afectada de enfermedades hereditarias, [que] estaba destinada a forzar una raza alemana fuerte e incontaminada» (Menvielle, 1937).

Sin embargo, las distancias entre la Iglesia católica y el Tercer Reich se acortaban cuando se trataba de exclusiones cuya praxis no dependiera de la intervención directa sobre los órganos de la reproducción. Ya en 1933 se había celebrado un Concordato entre el Vaticano y el gobierno alemán, y en adelante quedaría claro que era el marxismo un enemigo común. «El comunismo no es un fantasma. El comunismo es una realidad... No es un peligro, es la suma de todos los peligros que en el curso de la historia han podido oprimir a los pueblos», requiriéndose a través de los nacionalismos la aplicación de un «remedio eficaz contra él que no puede ser sino una medicación de cristianismo inyectado en todas las capas del cuerpo social» (Meinvielle, 1937).

El comunismo era parte de una otredad inasible que los nacionalismos prometían identificar para que, según la eugenesia adoptada, se desplegaran distintas estrategias dirigidas a evitar su propagación. En la tarea de promover la reproducción de los «mejores» (a tono con la llamada eugenesia positiva) tanto como en la de inhibir la propagación de «inferiores» (tal lo postulado por la denominada eugenesia negativa), se apuntaba a delimitar un universo homogéneo que resultaba necesario proteger de la amenaza disgénica de un "otro» externo a él que podía volverse incontrolable. Así funcionó esta forma de biopoder que prometía, a una población determinada, su inmunidad; esto es, la condición de refractariedad del organismo ante el peligro de contraer una enfermedad contagiosa (Esposito, 2005). Dentro de esta metáfora orgánica, la eugenesia proporcionaba su respuesta ante el mal identificado (podían ser enfermedades en sí tanto como ideologías "enfermas»), que se buscaba atacar interfiriendo en la capacidad de contagio (que equivalía a la de su reproducción). El rechazo a la eugenesia negativa no suponía situar a la Iglesia fuera de la lógica de un biopoder preocupado por detectar la otredad en la que anidaba el comunismo. Para intelectuales católicos ella estaba compuesta por herejes, impíos y/o proclives a prácticas 
neomalthusianas y según eugenistas argentinos como Arturo Rossi ${ }^{15}$, por quienes asumían características raciales precisas asociadas a minorías: los judíos, presentados como una raza inasimilable; los negros, sobre quienes se discutía el producto (humano o animal) de su cruza con blancos y/o el peligro amarillo (Rossi, 1944). Por su parte en otro eugenista, Vallejo Nágera, ese universo de la otredad podía quedar resumido en la detección del «gen rojo» (Huertas, 2002).

La diferencia identificada entre el nazismo y otros regímenes autoritarios europeos que combatían al comunismo radicaba en aquello que a los ojos del Vaticano constituían dos modos típicos de nacionalismo: uno pagano y otro cristiano. Obviamente, el nacionalsocialismo era expresión del primero, en tanto el régimen de Portugal y el de "la España que sangra» lo eran del segundo. Para Menvielle «un modo pagano [de nacionalismo] rechazará al extranjero porque es extranjero»; en cambio "un modo cristiano» lo hará «en la medida en que sea perjudicial para los intereses justos del propio país». Existía entonces «un modo pagano que rechazará y odiará al judío porque es judío» y "un modo cristiano que, conociendo la misión disolvente que le cabe al judío en el seno de los pueblos cristianos, limitará su influencia para que no resulte dañoso» (Meinvielle, 1937).

Portugal y España, junto a Italia asumirán en católicos argentinos un cúmulo de valoraciones positivas, como lo pondrá claramente de manifiesto César $\mathrm{Pico}^{16}$. En efecto, Pico también en 1937 recriminó la postura de Jacques Maritain al criticar los totalitarismos atacando por igual al fascismo y al comunismo ${ }^{17}$. El texto de Pico, redactado en forma de carta personal, y que contaba con el correspondiente nihil obstat de la Iglesia católica ${ }^{18}$, expresaba que:

La alianza de los católicos con un movimiento de esta especie [fascista] y sin que su cooperación implique un compromiso definitivo $-y$ aún menos de la Iglesia - no podrá objetarse en nombre de la incompatibilidad de los principios totalitarios con el dogma católico, por la sencilla razón de que tales principios no pertenecen a la esencia del movimiento. Más aún: desde un punto de vista práctico, esa cooperación facilitará al fascismo el hallazgo y la formulación de una doctrina que salvaguarde los derechos de la persona humana y lo aparte de la estadolatría (Pico, 1937, pp. 13-14).

Asimismo, destacaba que el fascismo había prestado grandes servicios a la Religión

no sólo combatiendo a sus peores enemigos, sino también favoreciendo la enseñanza religiosa y la difusión de la doctrina, restituyendo o afianzando el culto divino y las obras sociales, sosteniendo los derechos del matrimonio cristiano, exaltando las virtudes heroicas de los pueblos deprimidos por el utilitarismo y el sensualismo moderno, regulando, finalmente, las relaciones con la Iglesia mediante concordatos aceptados y deseados por la Sede Apostólica (Pico, 1937, pp. 20-21).

Entendiendo al fascismo como «el complejo de las fuerzas que reaccionan incluso con procedimientos drásticos, contra esa civilización moderna que termina dialécticamente en el comunismo», concluía en que era "lícito y conveniente colaborar en su gesta libertadora». (Pico, 1937, p. 40) $)^{19}$.

Aun dentro de esta apología general del fascismo invocando principios católicos, al igual que en Menvielle, quedaba afuera el "neo paganismo nacional socialista», el cual debía ser "ahora más que nunca, repudiado por los católicos» (Pico, 1937, p. 40).

Dentro de esta misma línea de pensamiento (aun cultivando una mayor moderación), Gustavo Franceschi ${ }^{20}$, director de la revista Criterio, criticó a Hitler por la ley de 1933 sobre el mantenimiento de la «pureza de la raza», afirmando que «importa la intervención del Estado en la procreación de los hijos y amenaza con la aplicación de las teorías formuladas por los eugenistas más radicales» (Franceschi, 1945, pp. 174-175).

Para distintos intelectuales católicos argentinos, la tensión entre "nacionalismo pagano» y "nacionalismo cristiano» era entonces, reductible, a una suerte de conflicto en torno a quién poseía competencia legítima para intervenir en el control de la reproducción: o era un régimen capaz de gestar su propia religión y confiar a científicos la aplicación de medidas extremas, o lo era la Iglesia católica universal, ya sea de manera autónoma o a través de un Estado que canalizara expresamente sus propósitos.

\section{EUGENESIA LATINA Y CATOLICISMO (O LO AMBIENTAL COMO EVANGELIZACIÓN DE LA OTREDAD)}

Como se ha visto, la postura netamente antieesterilizadora sostenida por la Iglesia católica no impidió que el Vaticano adoptara una variante de la ciencia de Galton, más concentrada en modificaciones ambientales que en lo que hoy podríamos denominar selección genética. Vale decir, fue parte sustancial en la conformación de aquello que se ha dado en llamar eugenesia latina, en oposición a la denominada eugenesia anglosajona, básicamente intervencionista en los cuerpos.

Invocando la autoridad de la preceptiva católica en el derecho argentino, Díaz de Guijarro recordaba al abate Dermine al sostener en el Congreso de la Association du Mariage Chrétien reunido en Marsella en 1930, que la moral cristiana no hacía más que interpretar la ley natural e imponer a los esposos el riguroso deber de asegurar a su descendencia toda la pureza y la salud requerida; deduciendo que era «un error profundo presentar a la moral cristiana como queriendo inconsiderablemente la multiplicación de la raza; no, señores, 
el punto de vista que domina toda la concepción cristiana de la moral conyugal es el de la calidad y no el del número» (Díaz de Guijarro, 1948, p. 28).

Criterio seguirá ocupándose del problema de seleccionar calidad, aun después de la Declaración Universal de Derechos Humanos, cuando puede decirse que en el plano internacional comienza una etapa de «eugenismo tardío» (Miranda, 2013). Lo hizo, por caso, transcribiendo fragmentos del libro de Louis-Marie Lalonde, Hérédité, donde se describían "cuatro actitudes» posibles ante la eugenesia: la de los «eugenistas radicales (materialistas)»; la de los «eugenistas moderados»; la de los "espíritus simples, muy ignorantes y prestos a cualquier credulidad»; y la actitud pasiva de los "tarados y de los mal dotados", de quienes sería de «interés disponer de ellos de modo que perjudiquen lo menos posible a la sociedad, que no dejen sus rastros en ella». Respecto a los «ignorantes», ellos debían ser instruidos sobre su propio valor hereditario, surgiendo entonces la necesidad de preconizar una enseñanza elemental de genética y la instauración de certificados que expresaran su estado de salud. Era necesario "resistir a los eugenistas exagerados, cualquiera sea su nombre y su fuerza», mientras que los "eugenistas moderados», aquellos que se proponen mejorar integralmente la naturaleza, sin violarla ni abatirla por otro lado», tendrían «derecho a nuestra más eficaz ayuda» (Lalonde, 1951, p. 660).

En definitiva, la pregunta era "¿̇a dónde quiere conducirnos la Eugenesia?». Y la respuesta contundente, planteada a renglón seguido, contenía una fuerte carga de maniqueísmo dirigida a que ningún católico fuera indiferente a ella: "a un estado excelente y deseable o a la ruina que es necesario impedir, según que los eugenistas tomen en cuenta o no al alma, según que sean cristianos o simplemente materialistas» (Lalonde, 1951, p. 662).

La vida humana quedaba así atravesada por la eugenesia, que podía resultar buena o mala según la articulación principal que ella entablara con la genética o con la religión, esto es, con saberes capaces de afirmar, de una u otra manera, su control sobre la sociedad. En cambio era impensable, desde la preceptiva católica, suponer un futuro sin eugenesia, o bien sin estrategias de poder intervinientes en la reproducción.

De este modo, la Iglesia, antes que una entidad que "desde afuera» condicionó el desarrollo de la eugenesia, resultó inherente a la definición de ese constructo, con toda su carga coercitiva desplegada a través del control de la moral. Aclarando la función normativa de esta eugenesia "ambiental» y antigeneticista, se invocaba a Pío XI para tener presente que «a los idiotas, los criminales o los ciertamente inaptos para el matrimonio» la autoridad «tiene el derecho y asimismo el deber riguroso de prohibir, de impedir y de castigar las unio- nes que repugnan a la razón y a la naturaleza», aunque se aclaraba, "sin mutilaciones, ya que otros medios resultan suficientes» (Lalonde, 1951, p. 664).

También Pío XII seguiría sosteniendo por años la vigencia de la Casti Connubii en la definición de una eugenesia deseable. Lo haría en 1953, al intervenir en el Primer Simposio Internacional de Genética Médica celebrado en Roma:

Se pretende obtener lo bueno y valioso, de afirmarlo, de promoverlo y de perfeccionarlo (...). Es preciso velar para que los caracteres positivos de pleno valor se unan con un patrimonio hereditario semejante. Tales son las tareas que se propone la genética y la eugenesia (...). La tendencia fundamental de la genética y de la eugenesia es influir en la transmisión de factores hereditarios para promover aquello que es bueno y eliminar lo nocivo; esta tendencia fundamental es irreprochable desde el punto de vista moral. Pero ciertos métodos para alcanzar el fin perseguido y ciertas medidas de protección, son moralmente discutibles (...).Cuando el portador de una tara hereditaria no es apto para conducirse humanamente ni, por consiguiente, para contraer matrimonio, o cuando más tarde se ha hecho incapaz de reivindicar por un acto libre el derecho adquirido por un matrimonio válido, se le puede impedir de una manera lícita el procrear un nuevo ser (...). Existe ciertamente el derecho $y$, en la mayor parte de los casos, el deber de advertir a aquellos que son realmente portadores de una herencia muy tarada, de la carga que pueden hacer gravitar sobre sí mismos, sobre su cónyuge y sobre su descendencia; esta carga puede llegar a ser intolerable. Pero desaconsejar no es prohibir (Pío XII, 1953).

Los mismos lineamientos se prolongarían en el VII Congreso de la Sociedad Internacional de Hematología, celebrado en Roma en 1958, donde el Sumo Pontífice volvió a rechazar las prohibiciones a la vez que enfatizaba la necesidad de ejercer un estricto control de la reproducción desde la moral católica (Pío XII, 1958).

Las repercusiones de este constructo en la Argentina proseguirían en el tiempo impactando especialmente en el Derecho, donde figuras como Bernaldo de Quirós y Díaz de Guijarro llevaran su propósito de propagar la eugenesia ambiental al plexo normativo civil. De hecho, también en 1958, tras sancionarse la ley que permitiría crear universidades privadas validadas por el Estado nacional consumándose una de las mayores conquistas alcanzadas por la Iglesia argentina y sectores afines, la articulación entre catolicismo y liberalismo confluiría en la creación de los estudios universitarios de eugenesia, a cargo de Bernaldo de Quirós (Vallejo, 2013).

El problema de la otredad como amenaza disgénica era, pues, afrontado en la versión eugénica latina a través de una vía de resolución más coherente con el dogma católico. Dado que el «otro» no tenía entidad 
admisible en tanto no se convirtiera a un «nosotros» controlado, la variable ambiental se constituía en una suerte de empresa evangelizadora de la reproducción.

La tenaz oposición de esta vertiente al determinismo biológico no conducía a un horizonte de ideas desprovisto de coerción. Cambiaban las estrategias seguidas, las que al ser menos estridentes en su aplicación también se volverían más efectivas y capaces de perdurar en el tiempo sin verse conmovidas por acontecimientos como la Declaración Universal de los Derechos Humanos. Esta cruzada ambiental lograría así sostener una «eugenesia tardía» (Miranda, 2013), anclada en un pensamiento abiertamente desfasado de los cambios

\section{NOTAS}

1 Esta perspectiva historiográfica fue inaugurada a partir de la publicación de: The hour of Eugenics (Stepan, 1991).

2 La tendencia a invocar apriorísticamente algunos conceptos de The hour of Eugenics, pasó a convivir con trabajos basados en otras miradas de la cuestión (García González y Álvarez Peláez, 1999); (Scarzanella, 1999); (Miranda y Vallejo, 2005); (Palma, 2005); (Vallejo y Miranda, 2008); (Ferla, 2009); (Miranda y Girón Sierra, 2009); (Vallejo y Miranda, 2010); (Miranda, 2011) y (Miranda y Vallejo, 2012), entre otros.

3 El padre Agostino Gemelli (1878-1959) -su verdadero nombre era Eduardo- en su juventud se había vinculado en la Facultad de Medicina de la Universidad de Padua con Camilo Golgi, premio Nobel de medicina. Abrazó el idealismo de Antonio Rosmini, Vincenzo Gioberti y Bertrando Spaventa y tomó los hábitos, afirmando esta decisión con el cambio de nombre adoptado para recordar a San Agustín. Fue Rector de la Universidad Católica de Milán, presidente de la Academia Pontificia, además de fundar y dirigir por años la revista Vita e Pensiero que tuvo una importante difusión en círculos católicos y laicos (Comacini, 2005); (Bocci, 2005); (Miranda, 2012); y, (Foschi, Giannone y Giuliani, 2013).

4 La cursiva es de Gemelli.

5 Nicola Pende (1880-1970) fue una reconocida figura del campo médico y social en la Italia de la primera mitad del siglo XX. Se formó en la escuela constitucionalista de Giacinto Viola y realizó sus primeros estudios en endocrinología clínica y experimental para luego formular su teoría biotipológica.

6 Sobre Pende fueron estudiados sus institutos (Vallejo, 2004); su modelo teórico (Galera, 2005), (Vallejo, 2005), (Cassata, 2006); la aplicación de ese modelo en Argentina (Miranda, 2005) y Brasil (Ferla, 2007)

7 Isidro Gomá, (1869-1940) fue Arzobispo de Toledo y Cardenal Primado de España actuando luego como representante de la Santa Sede ante el gobierno de Francisco Franco. Los documentos de su actuación fueron reunidos en lo que se dio en llamar el Archivo Gomá, objeto de una edición crítica que viene siendo publicada por tomos desde el año 2001 (AndrésGallego y Pazos, 2001) experimentados por la vida moderna, a la que misionalmente siguió tratando de evangelizar aun después de superada la primera mitad del siglo XX.

\section{AGRADECIMIENTOS}

Este trabajo se enmarca en los proyectos PIP-CONICET 114-201101-00379 dirigido por Gustavo Vallejo; PIP-CONICET 114-201101-00046 dirigido por Marisa Miranda (ambos en Argentina) y "Ciencia y creencia entre dos mundos. Evolucionismo, biopolítica y religión en España y Argentina», de referencia HAR201021333-C03-CO3, financiado por el Ministerio de Ciencia e Innovación (España).

8 Las deliberaciones, desarrolladas entre el 23 y el 25 de noviembre de 1934, fueron editadas ese mismo año (Actas, 1934). La homicultura era una disciplina que habían creado eugenistas cubanos vinculados a la línea más dura del eugenismo norteamericano. La Conferencia realizada en Buenos Aires sucedió a la primera, que tuvo lugar en diciembre de 1927 en La Habana, promovida por los norteamericanos Charles Davenport y Harry Laughlin y el cubano Domingo Ramos (Álvarez Peláez y García González, 1999).

9 Criterio pasó a ser, desde su nacimiento en 1928, la principal tribuna de opinión del pensamiento católico en Argentina.

10 Texto emblemático en materia de sexualidad en el matrimonio escrito por el ginecólogo holandés Theodoor Van de Velde con numerosas reediciones en distintos idiomas (Van de Velde, 1926)

11 Vallejo Nágera (1889-1960), fue jefe de los servicios psiquiátricos del ejército franquista durante la guerra civil española y uno de los psiquiatras más reconocidos por el nuevo Estado durante los primeros años de la dictadura (Huertas, 2002, pp. 89-114).

12 Enrique Díaz de Guijarro se graduó como abogado en 1928. Tuvo una destacada actuación académica en la Universidad de Buenos Aires, siendo además durante décadas una figura central en el Derecho Civil argentino. Participó protagónicamente en la Sociedad Argentina de Eugenesia desde su fundación, en 1945.

13 El abogado Carlos Bernaldo de Quirós (1895-1973) integró la Asociación Argentina de Biotipología, Eugenesia y Medicina Social. Fue fundador, en los años '30, del Instituto de la Población del Museo Social Argentino y, en la década siguiente, de la Sociedad Argentina de Eugenesia. Luego de ello, tuvo a su cargo el diseño y la dirección de la Facultad de Humanismo Integral y Eugenesia del Museo Social Argentino (Miranda, 2011); (Miranda, 2013); (Vallejo, 2013).

14 Julio Meinvielle (1905-1973) fue un sacerdote y filósofo tomista. De marcado pensamiento antisemita aunque opositor al nazismo, tuvo gran influencia en el pensamiento católico y nacionalista argentino. 
15 Arturo Rossi (1899-1944), se diplomó como médico en 1922 y de inmediato se especializó en el campo de la endocrinología y la biotipología. Durante la década de 1930 fue el principal impulsor de la eugenesia en Argentina.

16 César Pico era biólogo y se orientó hacia la teología y la filosofía, constituyéndose en una figura de referencia para el nacionalismo católico argentino. Inicialmente cobró notoriedad por ser uno de los fundadores de los Cursos de Cultura Católica en la década de 1920. Estos cursos constituyen un antecedente directo de lo que sería luego la Universidad Católica Argentina.

17 Jacques Maritain (1882-1973). Fue un filósofo neotomista francés que profesó ideas antitotalitarias. Entre agosto y septiembre de 1936 visitó la Argentina para dictar conferencias en los Cursos de Cultura Católica creados, entre otros, por César Pico. Al desatarse la Guerra Civil Española cuestionó la consideración de la misma como una "guerra santa», enfrentándose por ello a católicos integristas argentinos, entre los que se encontraría el propio Pico (Orbe, 2006).

\section{BIBLIOGRAFÍA}

Actas de la Segunda Conferencia Panamericana de Eugenesia y Homicultura de las Repúblicas Americanas (1934), Buenos Aires, Frascoli y Bindi.

Álvarez Peláez, Raquel y García González, Armando (1999), En busca de la raza perfecta. Madrid, CSIC.

Andrés-Gallego, José y Pazos, Antón (ed.) (2001), Archivo Gomá. Documentos de la Guerra Civil, Tomo 1. Madrid, CSIC.

Bernaldo de Quirós, Carlos (1960), Bases y principios para padres e hijos (Ensayo de Humanología Individual). Buenos Aires, Legión Blanca.

Bernaldo de Quirós, Carlos (1966), "Eugenesia y catolicismo", Estudios Eugenésicos, n 116, Buenos Aires, p. 209.

Blanco, Manuel (1946), Onanismo y cristianismo, Buenos Aires, s/d.

Bocci, María (2005), “Gemelli”. En: De Grazia, Victoria y Luzzatto, Sergio (a cura di), Dizionario del fascismo, Tomo 1, Torino, Einaudi, pp. 577-579.

Cafferata, Juan (1935), "Sobre la educación sexual, profilaxis antivenérea y certificado prenupcial", Criterio, n 403, Buenos Aires, pp. 281-283.

Cassata, Francesco (2006), Molti, sani e forti. Torino, Bollati Boringhieri.

Comacini, Gemma (2005), Gemelli. Il Machiavelli di Dio. Milán, Rizzoli.

Sobradillo, Agapito de (1943), El certificado médico prematrimonial. Universidad Pontificia de Salamanca.
18 El nihil obstat es la aprobación oficial desde el punto de vista moral y doctrinal de una obra que aspira a ser publicada realizada por un censor del Vaticano.

19 La cursiva es nuestra.

20 Monseñor Gustavo Franceschi (1881-1957), se constituyó en una figura central del pensamiento católico argentino e hispanoamericano durante buena parte del siglo XX. Dirigió la revista Criterio desde 1932 hasta su fallecimiento en 1957. Franceschi, nacido en Francia, había llegado a la Argentina en 1886 y, a los 23 años, se ordenó como sacerdote pasando a colaborar activamente con el padre Francisco Grote, organizador de los Círculos de Obreros Católicos. Franceschi luego integró la Liga Democrática, dirigió el periódico Justicia social y se ocupó de la organización de sindicatos cristianos. Poco antes de su muerte impulsó la formación del Partido Demócrata Cristiano.

Díaz de Guijarro, Enrique (1948), "La libertad, la moral y el amor ante los problemas jurídicos de la eugenesia", Jurisprudencia Argentina, sección Doctrina, Tomo 1948-I, Buenos Aires, pp. 22-31.

Esposito, Roberto (2005), Inmunitas. Protección y negación de la vida. Buenos Aires, Amorrortu.

Ferla, Luis (2007), “Cuerpo y comportamiento: el examen médicolegal en el Brasil de entreguerras". En: Vallejo, Gustavo y Miranda, Marisa (comps.), Políticas del cuerpo. Estrategias modernas de normalización del individuo y la sociedad, Buenos Aires, Siglo XXI, pp. 59-96.

Ferla, Luis (2009), Feios, sujos e malvados sob medida. A utopia médica do biodeterminismo. São Paulo (1920-1945). Sao Paulo, Alameda.

Foschi, Renato, Anna Giannone y Alessia Fiuliani (2013), "Italian Psychology under protection: Agostino Gemelli between Catholicism and fascism", History of Psychology, 16 (2), Washington D.C., pp. 130-144.

Franceschi, Gustavo (1932), “La Eugenesia”, Criterio, n² 218, Buenos Aires, p. 130.

Franceschi, Gustavo (Mons.) (1945), Obras completas. Tomo I, Totalitarismos, $1^{\circ}$ Parte (Nacionalsocialismo y fascismo). Buenos Aires, Difusión.

Galera, Andrés (2005), “Hacia una fisiología del delito: el modelo biotipológico de Nicola Pende". En: Miranda, Marisa y Gustavo Vallejo (comps.), Darwinismo social y eugenesia en el mundo latino, Buenos Aires, Siglo XXI, pp. 363-374. 
Gemelli, Agostino (1924), “L’Eugenetica e la morale cattolica. A proposito del $1^{\circ}$ Congr. Italiano di Eugenetica Sociale", Vita e Pensiero, XV (12), Milano, pp. 731-750.

Gomá, Isidro (1943 [1931]), El matrimonio. Explicación dialogada de la Encíclica Casti Connubii. Barcelona, Rafael Casulleras.

Gomá, Isidro (1934), "Apología de la Hispanidad", Acción Española, XI (64-65), Madrid, pp. 193-230.

Huertas, Rafael (2002), Los médicos de la mente. De la neurología al psicoanálisis. Madrid, Nivola.

Lalonde, Louis-Marie (1951), "El hombre actual y la eugenesia", Criterio, $\mathrm{n}^{\circ} 1146$, pp. 660-664.

Menvielle, Julio (1937), Entre la Iglesia y el Tercer Reich. Buenos Aires, Adsum, [en línea], disponible en:http://www.unilibrary.com/ ebooks/Meinvielle,\%20Julio\%20-\%20Entre\%20la\%20Iglesia\%20 y\%20el\%20Tercer\%20Reich.pdf [consultado el 23-08-2013].

Miranda, Marisa (2005), "La biotipología en el pronatalismo argentino (1930-1983)", Asclepio LVII (I), pp. 189-218.

Miranda, Marisa (2011), Controlar lo incontrolable. Una historia de la sexualidad en Argentina. Buenos Aires, Biblos.

Miranda, Marisa (2012), "La Argentina en el escenario eugénico internacional". En: Miranda, Marisa y Gustavo Vallejo (dir.), Una historia de la eugenesia. Argentina y las redes biopolíticas internacionales (1912-1945), Buenos Aires, Biblos, pp. 19-64.

Miranda, Marisa (2013), "La tardo-eugenesia en ámbitos latinos: Argentina y un enfoque desde la longue duree", Arbor, 189 (764), a088 doi: http://dx.doi.org/10.3989/arbor.2013.764n6011

Miranda, Marisa y Vallejo, Gustavo (comps.) (2005), Darwinismo social y eugenesia en el mundo latino. Buenos Aires, Siglo XXI.

Miranda, Marisa y Vallejo, Gustavo (dir.) (2012), Una historia de la eugenesia. Argentina y las redes biopolíticas internacionales (1912-1945). Buenos Aires, Biblos.

Miranda, Marisa y Girón Sierra, Álvaro (coords.) (2009), Cuerpo, biopolítica y control social. América Latina y Europa en los siglos XIX y XX. Buenos Aires, Siglo XXI.

Ochoa, Javier (1931a), "Al margen de la última Encíclica. De Eugenesia", Criterio, n¹52, pp. 147-148.

Ochoa, Javier (1931b), "Al margen de la última Encíclica. Las taras de la civilización", Criterio, n²157, pp. 309-310.

Ochoa, Javier (1931c), “Después de la Casti Connubii. Pornografía y falsa ciencia", Criterio, n²00, pp. 475-476.

O’Lery, María de las Mercedes (2008), “Aportes acerca de la relación Iglesia-eugenesia en Argentina (1930-1940)". En: Vallejo, Gustavo y Marisa Miranda (comps.), Políticas del cuerpo. Estrategias modernas de normalización del individuo y la sociedad, Buenos Aires, Siglo XXI, pp. 365-375.

Orbe, Patricia Alejandra (2006), "La concepción política de Jacques Maritain, eje de una controversia católica". En: Biagini, Hugo y Arturo Roig (dir.), El pensamiento alternativo en la Argentina del siglo XX. Tomo II: Obrerismo, vanguardia justicia social (19301960), Buenos Aires, Biblos.

Osés, Enrique (1931a), "La Santa Sede, la educación sexual y la eugenesia", Criterio, n 174, p. 7.

Osés, Enrique (1931b), "Otro ataque contra la familia", Criterio, n 140, p. 41.

Palma, Héctor (2005), Gobernar es seleccionar. Historia y reflexiones sobre el mejoramiento genético en seres humanos. Buenos Aires, Baudino.

Petrus Canisius (seud.) (1936), "Segundo Congreso Internacional de Médicos Católicos", Criterio, n 457, pp. 327-329.

Pico, César E. (1937), Carta a Jacques Maritain sobre la colaboración de los católicos con los movimientos de tipo fascista. Buenos Aires, ADSUM.

Pío XI (1930), Encíclica Casti Connubii, [en línea], disponible en: http://www.vatican.va/holy_father/pius_xi/encyclicals/documents/hf_p-xi_enc_31121930_casti-connubii_sp.html [consultado el 23/08/2013].

Pío XII (1953), Primer Simposio Internacional de Genética Médica, [en línea], disponible en: http://www.vatican.va/holy_father/ pius_xii/speeches/1953/documents/hf_p-xii_spe_19530907_ genetica_sp.html [consultado el 30/08/2013]

Pío XII (1958), VII Congreso de la Sociedad Internacional de Hematología, [en línea], disponible en: http://www.vatican.va/ holy_father/pius_xii/speeches/1958/documents/hf_p-xii_ spe_19580912_ematologia_sp.html [consultado el 30/08/2013]

Rossi, Arturo R. (1944), Tratado teórico práctico de biotipologia y ortogénesis, Tomo I. Buenos Aires, Editorial Ideas.

Sanvisenti, Bernardo (1931), "Una apostilla italiana a la Casti Connubbi", Criterio, $n^{\circ} 156$, p. 283.

Scarzanella, Eugenia (1999), Italiani malagente. Inmigrazione, criminalità, razzismo in Argentina, 1890-1940. Milano, Franco Angeli.

Stepan, Nancy Leys (1991), The hour of Eugenics. Ithaca and London, Cornell University Press. (Hay versión en portugués: Stepan, Nancy Leys (2005), A hora da Eugenía: raça, gênero e nação na América Latina, Río de Janeiro, Fiocruz).

Stern, Alexandra Minna (2005), Eugenic Nation. Faults and frontiers of better breeding in modern America. University of California Press.

Stern, Alexandra Minna (2010), "Eugenics, Gender, and Sexuality: A Global Tour and Compass". En: Bashford. A. and Levine, P. (eds.), The Oxford Handbook of the History of Eugenics, New York, Oxford University Press, pp. 173-191.

Toth, Tihamer (1940), Eugenesia y Catolicismo. Madrid, Editorial Sociedad Atenas.

Vallejo, Gustavo (2008), “Cuerpo y representación: la imagen del hombre en la eugenesia latina". En Vallejo, Gustavo y Marisa Miranda (comps.), Políticas del cuerpo. Estrategias modernas de normalización del individuo y la sociedad, Buenos Aires, Siglo XXI, pp. 23-58. 
Vallejo, Gustavo (2004), "El ojo del poder en los espacios del saber: los institutos de biotipología”, Asclepio LVI (1), pp. 219-244.

Vallejo, Gustavo (2005), "Las formas del organicismo social en la eugenesia latina”. En: Miranda, Marisa y Vallejo, Gustavo (comps.), Darwinismo social y eugenesia en el mundo latino, Buenos $\mathrm{Ai}$ res, Siglo XXI, pp. 231-272.

Vallejo, Gustavo (2007), "Males y remedios de la ciudad moderna: perspectivas ambientales del eugenismo argentino de entreguerras", Asclepio LIX (1), pp. 203-238.

Vallejo, Gustavo (2013), “Una eugenesia liberal y católica en la segunda posguerra. Argentina en la década de 1960". En: Calvo, Luis, Álvaro Girón y Miguel Ángel Puig-Samper (ed.), Naturaleza y laboratorio, Barcelona, Residència d'Investigadors, pp. 265-296.
Vallejo, Gustavo y Miranda, Marisa (comps.) (2008), Políticas del cuerpo. Estrategias modernas de normalización del individuo y la sociedad. Buenos Aires, Siglo XXI.

Vallejo, Gustavo y Miranda, Marisa (dirs.) (2010), Derivas de Darwin. Cultura y política en clave biológic., Buenos Aires, Siglo XXI.

Vallejo Nágera, Antonio (1938), Eugamia. Selección de novios. San Sebastián, Editorial Española.

Vallejo Nágera, Antonio (1943), “Prólogo". En: Sobradillo, Agapito de, El certificado médico prematrimonial, Salamanca, Universidad Pontificia de Salamanca.

Van de Velde, Theodoor Hendrik (1926), Het volkomen huwelijk. Leyden Publishing Company. 